\title{
Psicologia e políticas inclusivas na Educação: contribuições de uma leitura Bakhtiniana
}

\section{Psychology and inclusion policies in Education: contributions from a Bakhtinian reading}

\section{Psicología y políticas inclusivas en la Educación: contribuciones de una lectura Bajtiniana}

\author{
Miriam Aparecida Graciano de Souza Pan* \\ Universidade Federal do Paraná - UFPR, Curitiba, Paraná, Brasil
}

\section{Maiana Jugend Zugman**}

Tribunal de Justiça do Paraná - TJPR, Curitiba, Paraná, Brasil

\begin{abstract}
RESUMO
A inclusão constitui-se discurso dominante nas práticas contemporâneas de educação, sendo um desafio aos profissionais da Psicologia. Este trabalho apresenta uma análise de uma prática de intervenção do psicólogo em uma escola pública de Curitiba. Tem por objetivo refletir sobre a dimensão intersubjetiva das práticas escolares configuradas pelas políticas de inclusão e as contradições presentes no enfrentamento destas políticas, a partir dos pressupostos bakhtinianos, entendendo-se a escola enquanto instituição imersa na totalidade social e histórica, produzida simbolicamente pelo princípio do dialogismo. Foram analisados registros e materiais produzidos em 2004 e 2005. Os resultados evidenciaram relações ensurdecidas na escola, caracterizadas pela prevalência do monologismo, presente nos discursos dos atores da instituição em todos os níveis. A prática analisada apontou um método de intervenção e investigação, visando escutar e fazer circular vozes, produzindo, na arena de vozes, formas de reconhecimento da ruína das relações de alteridade. As dimensões ética e política da intervenção apresentaram-se como forma de enfrentamento das contradições presentes nos discursos da inclusão.
\end{abstract}

Palavras-chave: intervenção psicológica, inclusão, dialogismo, educação.

\begin{abstract}
Inclusion is a dominant discourse in the contemporary practices of education, and a challenge for professionals in the field of Psychology. This study presents an analysis of a psychologist's intervention in a state school in Curitiba. It aims to cast a light upon the intersubjective dimension of the schools' practices, constituted by the inclusion policies and the contradictions in confronting theses policies. The analysis was carried out based on Bakhtinian theories, which regard the school as an institution immersed in a social and historical totality, symbolically produced by the dialogism principle. We analyzed the records and the material collected in 2004 and 2005. The results revealed deafened relations in the school: the movement
\end{abstract}


of social voices is characterized by the prevalence of monologism, present in the discourses of the actors within the institution at all levels. The analyzed practice pointed to a method of intervention and investigation, which aims to listen and to make the voices circulate, while producing, in the arena of voices, ways of recognizing the disruption in the relations of alterity. The ethical and political dimensions of the interventions presented themselves as a way of facing the contradictions in the discourses of inclusion.

Keywords: psychological intervention, inclusion, dialogism, education.

\begin{abstract}
RESUMEN
La inclusión se constituye en un discurso dominante en las prácticas contemporáneas de educación, siendo un desafío a los profesionales de la Psicología. Este trabajo presenta un análisis de una práctica de intervención del psicólogo en una escuela pública de Curitiba. Tiene por objetivo reflexionar sobre la dimensión intersubjetiva de las prácticas escolares configuradas por las políticas de inclusión y las contradicciones presentes en el enfrentamiento de estas políticas, a partir de los presupuestos bajtinianos, entendiéndose la escuela como institución sumergida en la totalidad social e histórica, producida simbólicamente por el principio de dialogismo. Fueron analizados registros y materiales producidos en 2004 y 2005 . Los resultados evidenciaron relaciones ensordecidas en la escuela caracterizadas por la prevalencia de monologismo, presente en los discursos de los actores de la institución en todos los niveles. La práctica analizada apuntó un método de intervención e investigación, permitiendo escuchar y hacer circular las voces, produciendo, en la arena de voces, formas de reconocimiento del desmoronamiento de las relaciones de alteridad. Las dimensiones ética y política de la intervención se presentaron como una forma de enfrentamiento de las contradicciones presentes en los discursos de la inclusión.
\end{abstract}

Palabras Clave: intervención psicológica, inclusión, dialogismo, educación.

\title{
1 Introdução
}

O Governo brasileiro instituiu a inclusão escolar nos últimos 20 anos como política nacional prioritária, assumindo uma agenda internacional de compromissos com a universalização da educação básica. O discurso da inclusão passa a afirmar-se na área da educação como um novo paradigma, sustentando-se em políticas internacionais como a Declaração Mundial sobre Educação para Todos (UNESCO,1998) e a Declaração de Salamanca, (MEC,1994). Leis e Diretrizes nacionais estabeleceram a universalização da educação básica no Brasil. Os Planos Nacionais de Educação (2001 e 2014) vêm operacionalizando a destinação de recursos e políticas públicas que visam garantir a todos o acesso à educação fundamental.

A educação escolar, segundo diferentes perspectivas, deve propiciar o domínio da leitura, da escrita, da linguagem dos números e da natureza, de modo a possibilitar a transformação da sociedade, a apropriação do conhecimento produzido historicamente pela humanidade, oportunizando condições emancipatórias e de cidadania. A imersão nas práticas sociais de leitura e escrita tem, nesse sentido, 
consequências sociais, políticas, cognitivas, linguísticas, subjetivas e econômicas para as pessoas e os grupos sociais, de maneira a alterar o seu "estado" ou "condição" (Pan, 2007).

A Psicologia deve enfrentar o desafio de intervir no contexto concreto das escolas diante da complexidade resultante das políticas inclusivas, reinventado suas práticas. Considera-se relevante compreender os cenários mais amplos implicados nessas políticas, suas contradições e seus efeitos nas práticas escolares e nos processos de produção subjetiva decorrentes. Esses elementos podem elucidar uma análise crítica das condições concretas que o psicólogo depara-se ao intervir em uma escola, a fim de promover a inclusão.

\section{Educação em tempos de neoliberalismo e as políticas inclusivas}

A escola reflete e refrata a sociedade da qual ela faz parte. Constituise em uma instituição de referência na subjetivação de crianças e jovens, podendo ser entendida como microcosmos do espaço público ampliado no qual ela se insere. A educação, enquanto uma das diversas práticas sociais institucionalizadas, reflete as contradições, tendências e interesses da sociedade (Laplane, 2004; Coutinho, 2011).

Se analisada da forma como se organiza atualmente, a sociedade é excludente, dualizada. Desde a Antiguidade Clássica são evidenciadas situações de exclusão social, as quais provocavam uma desigualdade explícita entre os cidadãos que habitavam e os que não habitavam os intramuros das cidades, sendo considerados não-cidadãos; os "bárbaros" (Carone, 1998).

Com a lógica capitalista e o pensamento hegemônico que o caracteriza na contemporaneidade, o neoliberalismo, a sociedade se transformou em uma ordem assentada no movimento de capitais e lucros, em que tudo se transforma em valor mercantil. As políticas neoliberais atuam para satisfazer as necessidades dos cidadãos que se constituem na condição de consumidores. É o direito individual de propriedade, isto é, o direito de comprar e vender. A desigualdade que promove as possibilidades de compra e venda é o que leva os indivíduos a melhorar, esforçar-se e competir (Gentili, 1997).

$\mathrm{Na}$ escola o que ocorre não é diferente, já que esta se encontra inserida no modelo neoliberal de relação Estado-sociedade. Segundo Laplane (2004), "a compreensão da própria ideia de inclusão e das formas que as políticas inclusivas assumem está estreitamente relacionada ao modo como se caracteriza a dinâmica social" (p. 01). A educação deve ser universalizada para sustentar a livre iniciativa e as relações de competitividade, e não como uma necessidade 
constitutiva do homem. O modelo escolar pretensamente para todos harmoniza-se com o discurso da igualdade de direitos e oportunidades e acaba, muitas vezes, operando às avessas, contribuindo para a produção da exclusão daqueles que não se encaixam na normatividade disciplinar (Laplane, 2004; Coutinho, 2011).

O sucesso e o fracasso desses estudantes são explicados como decorrentes do desenvolvimento das habilidades naturais; assim como a natureza, os mais capazes devem triunfar. É a valorização do mérito individual, que contribui para a difusão da ideia de responsabilidade direta das pessoas sobre seu sucesso ou fracasso.

A escola, sob efeito desse discurso, imputa a crença de que as oportunidades de crescimento e desenvolvimento são as mesmas. Consequentemente, as desigualdades de rendimento são interpretadas como naturalmente inerentes aos alunos, os quais assumem o fracasso como algo próprio, natural e individual, sendo eles culpabilizados. Assim, circulam na escola concepções patologizantes de qualquer dificuldade ou fracasso escolar, explicados pela falta de capacidade do aluno, e não pela falta de adequação do processo pedagógico (Kassar, 2004).

Segundo Rocha (2010), "os sujeitos são tomados isoladamente e a tentativa de compreendê-los gera classificações que fortalecem a lógica binária: a criança é lenta ou acelerada demais; é apática ou violenta; qual o diagnóstico?" (pp. 72-73).

Carone (1998) afirma que o Estado democrático, para manter a igualdade, "... deveria ignorar a múltipla heterogeneidade das necessidades e sentimentos do homem, advindos de um processo civilizatório de desigualdades crescentes, a fim de uniformizar, homogeneizar e nivelar as necessidades e sentimentos a um grau básico, 'natural'"' (p. 176).

A homogeneização dos alunos gera um ensino indiferenciado, que impede a exploração da plasticidade do funcionamento humano, o que faz com que, diante de uma população heterogênea de crianças, forme-se, dentro da instituição escolar, uma parte de alunos marginalizados do processo educacional. Produz-se, desta forma, uma exclusão velada dentro da escola, em que crianças diferentes são tratadas como iguais, sem que suas particularidades sejam percebidas e nem as suas necessidades atendidas (Laplane, 2004).

Portanto, a contradição do discurso da inclusão produz-se como efeito da tensão presente no cotidiano das práticas escolares, onde a lógica homogeneizante se reproduz em forma de direito de oportunidades indiferenciadas, sendo justamente a diferença que deve ser levada em consideração. Como, então, enfrentar as contradições do discurso da inclusão? Como entender e intervir neste contexto contraditório em que a inclusão se coloca como tarefa prioritária ao psicólogo escolar? Como atuar num ambiente velado de exclusão, em que o 
sofrimento e a queixa escolar permanecem localizados no aluno, presentificando-se como a principal demanda ao psicólogo?

\section{A análise do discurso da inclusão a partir da perspectiva de Mikhail Bakhtin e os desafios à Psicologia}

Assim como todas as esferas da atividade humana, a escola é uma instituição concreta, situada historicamente na sociedade em que está inserida, que reflete e refrata seus valores e as relações de poder nela inscritas. As relações humanas, segundo os fundamentos bakhtinianos, só ocorrem mediadas semioticamente, já que vivemos em um mundo de linguagem, signos e significações (Faraco, 2003). Estes signos são intrinsecamente sociais e decorrem da heterogeneidade dos sentidos das experiências vividas pelos grupos humanos em determinadas épocas, ao longo da história.

Uma instituição pode ser analisada pela utilização dos signos por ela refletidos e refratados nas relações humanas de seu cotidiano, sendo o principal deles, a língua. Esta se constitui como signo ideológico atravessado por sentidos e valores, que se afirmam como verdades, como discursos e vozes sociais que se contrapõem, misturam-se, renovam-se e se negam, encontrando-se em constante movimento dialógico (Pan, 2003).

O dialogismo é uma categoria central no pensamento bakhtiniano. As relações dialógicas encontram-se em constante tensão e conflitos, retratando a dinâmica viva da língua, o processo de produção de sentidos e a arena de confronto entre os diferentes grupos sociais. Refletir sobre as relações presentes no contexto escolar é reconhecer as contradições dos sentidos que permeiam este cotidiano.

Desse modo, o desafio que se apresenta ao psicólogo que atua na educação formal diante da inclusão é, primeiro, pensá-la discursivamente, ou seja, enquanto instituição concreta situada em uma arena de vozes; segundo, buscar maneiras de "desestabilizar relações de forças, interromper discursos monologizantes" e seus efeitos de verdade universal, dada naturalmente, e que determinam os modos de ser "normal e anormal" nas práticas educativas contemporâneas, produzindo "outros efeitos de sentidos que possibilitem pensar outros modos de vida" (Pan, 2007, s/p).

Os pressupostos bakhtinianos oferecem elementos que possibilitam a proposição de modelos de análise que subsidiem uma intervenção institucional, favorecendo outras leituras para as práticas de exclusão velada, preconceitos, identidades fixadas em padrões de normalidade e anormalidade e produtoras de modos de subjetivação assujeitados. Essas leituras, em sua dimensão ética, podem também possibilitar a criação de meios de circulação de vozes dentro da instituição escolar, 
a dessacralização para com o instituído, o estranhamento para com a ruína das relações de alteridade.

Segundo Rocha (1999), por mais que atue na promoção das mudanças almejadas pela Psicologia, o psicólogo escolar encontra dificuldades em definir modelos de atuação, considerando os modelos clássicos: clínico, pedagógico ou institucional. A crítica da autora dirige-se às concepções tecnicistas, mecanicistas, lineares e hierarquizadas de ensino e currículo nelas presente. Propõe como desafio ao psicólogo escolar a superação dessas práticas e uma leitura das problemáticas que não perca de vista a totalidade social e histórica e ao mesmo tempo possa subsidiar intervenções eticamente orientadas.

Sendo assim, o presente estudo visa analisar a dimensão intersubjetiva das práticas escolares configuradas pelas políticas de inclusão e as contradições presentes no enfrentamento destas políticas por parte da psicologia escolar, a partir da perspectiva bakhtiniana.

\section{Método}

Este trabalho é uma análise documental, de caráter discursivodialógico, do registro de dados de uma intervenção em psicologia educacional realizada em uma escola pública de Curitiba, em 2004 e 2005, como parte da pesquisa "Práticas de Letramento e Processos Subjetivos: um estudo sobre exclusão escolar", da Universidade Federal do Paraná. A Pesquisa possui um banco de dados sistematizados dos registros das atividades realizadas em diferentes contextos educacionais que se definiam inclusivos. Estas atividades seguiam a proposta delineada pelo projeto de extensão "Letramento e Inclusão Social", cuja prática era desenvolvida pela equipe composta por alunos do curso de Psicologia e pela professora coordenadora dos Projetos. Os estudantes eram qualificados para efetuar intervenções em diferentes instituições educacionais, produzindo, assim, os dados sistematizados e analisados na Pesquisa. Os dados constituíam-se por registro de entrevistas, observações e reuniões, materiais produzidos durante atividades desenvolvidas com alunos, professores e demais participantes do Projeto, como desenhos, fotografias e textos. Além disso, compunha o banco de dados os diários de campo compostos pela descrição pormenorizada do ocorrido durante todos os dias em que a equipe de Psicologia esteve na escola. Esses dados eram previamente sistematizados em um relatório, pela equipe que realizava a intervenção na instituição concreta em que o Projeto de Extensão era desenvolvido.

Diante das condições de produção dos dados, as presentes pesquisadoras debruçam a sua leitura sobre o ocorrido em uma 
escola pública que atendia 1400 alunos, sendo 1100 de $1^{\mathrm{a}}$ a $8^{\mathrm{a}}$ séries do Ensino Fundamental, que estudavam no período diurno, e 300 do Ensino para Jovens e Adultos (EJA), no período noturno. Os estudantes do Ensino Fundamental caracterizavam-se, segundo os registros consultados, em sua maioria, como pertencentes à classe econômica média. Já os alunos do EJA eram de classe socioeconômica baixa, os quais não tiveram acesso ou continuidade regular de estudos no Ensino Fundamental.

A primeira leitura dos dados seguiu uma dimensão temporal. Essa leitura dos materiais indica que, inicialmente, o trabalho ocorre sob o caráter de uma investigação diagnóstica das relações intersubjetivas presentes na escola, visando identificar focos de sofrimento nos relatos dos sujeitos e as demandas para uma intervenção psicológica. Posteriormente, são descritas nos registros as metodologias empreendidas de modo participativo na intervenção, em forma de oficinas. São definidas como atividades temáticas que ocorrem como diferentes formas de expressão, construídas a partir da caracterização inicial do grupo.

Por meio da análise dos documentos, depreendeu-se que 0 diagnóstico institucional possibilitou a criação de um plano de intervenção com enfoque em uma queixa evidente de sofrimento presente na escola em questão: de que alunos e professores não se escutavam, sendo destinada especialmente às quatro turmas de $6^{a}$ série, consideradas problemáticas. Foi desenvolvido o projeto "Saber Escutar", realizado com cada turma por meio de cinco oficinas de música, em encontros semanais. As atividades ocorriam com diversas canções, de forma que os alunos as ouviam e depois discutiam a respeito do sentido da música ouvida, do seu contexto, da forma como se identificavam com a letra e da relação entre a composição e a realidade escolar.

Na primeira leitura, a temporalidade nos ajudou a compreender a sequência da intervenção realizada. Empreendeu-se então uma segunda leitura, na qual se buscou identificar elementos discursivos que indicassem os processos de produção de sentidos na instituição, perpassados por práticas configuradas pelas políticas de inclusão escolar. Para tanto, foram analisados todos os registros produzidos e registrados pela equipe de Psicologia que atuou na escola. Fragmentos de fala e atividades realizadas pelos alunos da instituição, incluindo desenhos, foram extraídos pelas pesquisadoras da maneira como constavam nos documentos, para serem aqui reproduzidos e aprofundados, a fim de viabilizar o diálogo entre as relações presentes na escola, as pesquisadoras e o mundo social.

O olhar empreendido parte dos pressupostos da análise do enunciado, fundamentada pelos princípios da teoria bakhtiniana e discutidos em suas possibilidades e limites para a pesquisa em ciências humanas (Jobim e Souza \& Porto e Albuquerque 2012; 
Machado \& Pan, 2012; Amorim, 2012). Essa perspectiva apresenta-se como alternativa fértil para a leitura de textos históricos e documentos (Machado \& Pan, 2012; Castro, Portugal, \& Jacó-Vilela, 2011). Aqui nós a utilizamos para a leitura dos registros de uma prática psicológica.

Os autores do chamado Círculo de Bakhtin convergem na definição do enunciado como um texto vivo, ou seja, a palavra carrega em si os valores de uma dada sociedade (Bakhtin, 1990). Jobim e Souza, Camerini e Morais (2000) afirmam que pela palavra é possível apreender movimentações de (re)construção e de degradação de significações que produzem efeitos de sentidos sobre modos de subjetivação em um dado momento histórico, compondo os cenários das experiências cotidianas de uma sociedade. A linguagem é lugar de produção de sentidos entre sujeitos situados socialmente e historicamente.

Amorim (2012) defende que o que se impõe como horizonte e limite do texto de pesquisa é a espessura discursiva, pois a construção de sentido de todo discurso é inacabável. Assume-se, assim, a impossibilidade de restituição do sentido originário do que foi dito na escola, uma vez que o texto da pesquisa constitui-se sempre como um novo (con)texto. Nesse sentido, este texto utiliza-se de narrativas e transcrições de fragmentos de diálogos presentes nos registros, sem, contudo, trazer em si o mesmo sentido do ato singular e concreto de interlocução ocorrido na escola em estudo, pois os diálogos constituem-se aqui como outro enunciado, produzido e direcionado a outro (con)texto.

Nesses registros liam-se as dificuldades enfrentadas pela instituição para a implantação das políticas inclusivas e as contradições presentes em suas práticas. Todo o material resultante das práticas psicológicas realizadas na escola foi minuciosamente analisado com o intuito de se compreender responsivamente os sentidos atribuídos pela instituição, de modo a se produzir o diálogo ético e o compromisso epistemológico entre os pesquisadores e o texto de pesquisa. Assim, os dados foram analisados a partir da constituição de uma rede de diálogos (Faraco, 2003) entre os textos do banco de dados e os pesquisadores, visando construir um novo texto, configurado por outras condições dialógicas possíveis entre 0 pesquisador e seus leitores, a fim de produzir outros efeitos de sentidos acerca das práticas educativas em contextos formais de educação e das possibilidades de leitura e atuação da Psicologia na Educação.

\section{Resultados}


A proposta de intervenção "Saber Escutar" foi elaborada participativamente pela equipe do Projeto de Extensão a partir da queixa escolar a respeito da não-escuta, no início de 2005. Este período foi marcado por reuniões com a escola sobre as possibilidades de horários, a sala de aula disponibilizada às atividades sugeridas e a liberação das disciplinas curriculares para a realização das oficinas de música.

No material analisado, percebe-se que as discussões tomaram parte tão grande do tempo que as oficinas não foram iniciadas no período previsto. Nesse ínterim, foi possível ler o embate entre os sentidos da inclusão que se presentificavam na escola por meio das demandas à equipe de Psicologia, objetivado nas queixas de alunos com dificuldades e de turmas indisciplinadas, que não ouviam os professores, coordenadores ou direção da escola. A partir da implantação das políticas de inclusão, as perspectivas de encaminhamento de alunos ou separação de turmas especiais não são mais possíveis.

Produtivamente, a ação do Projeto propagou uma discussão sobre o ensurdecimento na escola, levando a uma reflexão em todos os níveis: direção, orientação, professores, retirando o foco que caía apenas sobre os alunos. Em termos bakhtinianos pode-se identificar nesse processo a possibilidade de se tecer a arena de vozes que compunha o cotidiano da instituição em análise. Vamos a ela.

\subsection{Bagunça x Indiferença}

Os registros das entrevistas realizadas pela equipe de Psicologia com professores, funcionários e equipe pedagógica da escola evidenciaram os sentidos atribuídos quase unanimemente aos alunos: agressivos, conturbados, desrespeitosos, briguentos, violentos e indisciplinados. Adjetivos esses endossados pelos próprios alunos.

Sobre a relação aluno-aluno leu-se "... sem respeito", com ilustrações típicas: "eles batem no outro, eles chutam" e "eles não têm o mínimo respeito e consideração". Ao serem indagados sobre soluções propostas ao problema apontado, a maioria afirmou não saber lidar com isso ou não considerar possível alguma solução.

Sobre a relação professor-aluno, um funcionário se posicionou: "A gente vê que tem professor que leva cada baile! Hoje eu tava quase entrando na sala com vassoura e tudo e dizendo: 'Sosseguem!'". A incapacidade de criar alternativas para enfrentar as situações de agitação por parte dos alunos mobilizava toda a escola.

Sob efeito de tais discursos, os professores relatavam sentirem-se desvalorizados, já que as crianças e jovens "... não se envolvem muito; você e nada dá no mesmo". Diante disso, para que os alunos se engajassem nas atividades curriculares propostas pelos professores, tudo deveria valer nota. Se não valesse nota, eles se 
desmotivavam e não cumpriam a tarefa. O uso dessas práticas ameaçadoras, conforme pode ser lido nos registros, aumentava a tensão das relações, levava à separação dos grupos e à produção e reprodução de seus estigmas por meio de discursos permanentes de rotulação e culpabilização. A equipe de Psicologia registra constantemente em seus diários de campo, as suas impressões pessoais em permanente indagação: Quais seriam, então, os sentidos possíveis para a inclusão? Qual seria o significado do saber escutar? Uma professora, durante entrevista descrita nos documentos analisados, enunciou sua frustração com esse tipo de prática: "Pra gente é frustrante. $O$ aluno não produz, não consegue ir além, pouquíssimos são os alunos que te questionam e pouquíssimos são aqueles que querem mais. Então sabe aquela coisa gostosa de 0 aluno te colocar no canto, de te trazer desafios? Isso não existe. Essa baixa produção é muito frustrante, então você começa a se questionar se o erro está em você, se está no aluno... Como é que eu vou fazer o aluno produzir? Então você tenta motivar, trazer coisas diferentes, sobre drogas, uso de armas, mas se você vir o tipo de resposta que ele traz, é assim: 'Não tô nem aí'".

A equipe de Psicologia atuando na escola deparou-se com similar dificuldade, tal como constava nos diários de campo: "Os alunos não nos escutavam"; "Havia falta de atenção a nossa proposta e ... falta de participação da turma ..., pois a turma ficava dispersa e era difícil termos o controle" (Poças, Quandt, Jamus, \& Menegusto, 2005, p. 5). Nos diversos sentidos atribuídos aos alunos e às relações escolares, uma similaridade pôde ser apreendida: a bagunça, o desrespeito e a indiferença produzindo apatia e desmotivação na escola. Afinal, ensinar e aprender para quê?

\section{2. "Tenho direito de expressar-me. Sou proibida de expressar-me. Expressar-se: será que isso é crime?"}

De que forma os alunos significavam-se no contexto escolar? Como essas crianças e jovens se representavam em meio a um ambiente permeado por discursos que estabeleciam verdades e incontáveis valorações sociais? A equipe de Psicologia registrou nos diários de campo suas possíveis hipóteses sobre o que ocorria no cotidiano escolar: "Fala-se sobre as crianças, das crianças, mas não com as crianças". Afirmaram, em seus planos de trabalho, que falar com os alunos, os protagonistas de toda a história, era o primeiro passo para que eles pudessem ser ouvidos.

Os enunciados: "Tenho direito de expressar-me. Sou proibida de expressar-me. Expressar-se: será que isso é crime?" foram produzidos por uma aluna da $8^{a}$ série. A atividade, proposta pela equipe da Psicologia, solicitava que as crianças desenhassem como era, para elas, estudar nesta escola. A frase em questão apareceu 
conjuntamente ao desenho de uma pessoa com venda nos olhos e algema nos punhos. Olhos vendados e mãos atadas podem ser compreendidos como o sentimento de impotência do aluno face à atividade formal da escola. De olhos e mãos atados o lugar para manifestação e criação parece escasso; suas vozes não conseguem ser ouvidas. Outra aluna da $8^{a}$ série também verbalizou esta questão: "Não somos ouvidos a maioria das vezes". Esse posicionamento diante das figuras de autoridade da escola reproduziam-se em diferentes atividades das oficinas em forma de clichês, como: "ditadura", "ditadora", "calem-se".

Se a bagunça e a indiferença forem entendidas como a forma de resposta dos alunos na cadeia discursiva, esta resposta toma, ainda, outra maneira: a dificuldade de se expressarem e de serem ouvidos. As oficinas deram forma a uma voz excluída, que os permitiu expressar o modo como se sentiam na escola, ao serem rotulados de bagunceiros ou apáticos. Incluí-los então, toma o sentido de incluídos no diálogo.

\subsection{Escola e família: de quem é a culpa?}

Mediante as dificuldades encontradas no cotidiano da escola em questão, muitos discursos de culpabilização às famílias dos alunos foram registrados nas entrevistas: "... aquele aluno que tá dando problema na escola, tanto de aprendizagem, tá dando problema aqui porque tem problema em casa". O aluno-problema já chegava à escola como um filho-problema, pois "quando há problemas na escola, eles estão vindo de fora" (diretoria).

Nos discursos da escola, a família era significada como uma instituição falha que, devido à ausência dos pais, não tem controle sobre seus filhos e não sabe lhes impor limites: "... essa geração é a geração mais abandonada que tem. Os pais trabalham o tempo todo, eles estão sozinhos, então eu não sei se, em decorrência disso, eles estão largados...".

O discurso da instituição presentificava intensamente a queixa pela responsabilização da educação que julgava não caber à escola, mas à família: "A escola é médica, psicóloga, atende todos os setores. A escola dá remédio... Abrange uma série de funções que não é a sua, que é repassar a informação, o conteúdo que eles precisam e que foi acumulado pela humanidade. Os pais agem na escola como um depósito: eles colocam os filhos aqui, porque os filhos estão seguros, ou mais seguros do que estariam na rua. Exigem que a gente eduque. Nós temos que fazer a educação sexual, a educação de higiene... Então a escola é um depósito seguro para os filhos, porque tem que fazer tudo" (professora).

Os dados mostraram a culpabilização em relação aos problemas enfrentados pelos atores institucionais, às famílias, o que parece 
isentá-los de suas responsabilidades em relação as suas causas e a sua insolubilidade.

\subsection{O papel da Psicologia}

Nas entrevistas realizadas pela equipe de Psicologia, perguntava-se: "Qual a necessidade que você apontaria para o trabalho de um psicólogo aqui na escola?". As respostas foram variadas. Para os professores leu-se o sentimento de incapacidade e despreparo para lidar com os problemas, bem como se apontou a necessidade para o acompanhamento não apenas dos alunos de inclusão, mas de todos os alunos: "Às vezes o aluno é o que é em sala porque não tem um acompanhamento psicológico. De repente ele até tem um distúrbio psicológico e ninguém percebe; o professor não tá preparado".

Para outros profissionais, o psicólogo propiciaria um espaço de escuta: "Não é só com o aluno, mas com os pais também em geral, com o próprio funcionário que às vezes não tá desempenhando bem o seu serviço e não tem com quem se abrir. O psicólogo seria bom".

Depreendeu-se também no discurso de uma professora uma demanda mais ampla: "Eu acho que a gente precisa do trabalho do psicólogo junto ao corpo docente, porque nós estamos cada dia mais desgastados e sem saber lidar com isso. E junto aos alunos, em trabalhos diferenciados [como] motivação, sentido, o porquê, porque têm muitas coisas que eles não sabem o porquê. Eles tão gritando só porque tão gritando. E a gente não tem subsídios para trabalhar com eles, falta instrumentalização pra gente, de saber como lidar com o adolescente, com aquele comportamento. Então, esse trabalho de apoio, tanto pra gente, quanto pro aluno, seria fundamental".

O sentido da Psicologia na escola poderia ser demonstrado por meio de vários outros registros presentes nos materiais analisados. Todos eles se justificavam através de queixas, demandas e esperanças de que o psicólogo interviesse nos diversos tipos de sofrimento ali presentes, trazendo melhoras as relações escolares.

Os dados analisados retrataram a escola como uma instituição habitada por uma multidão de vozes, desejos, sentidos e enunciados, caracterizando a dimensão subjetiva das práticas escolares. Paradoxalmente, há a predominância do discurso da inclusão, que impõe à instituição a obrigação de garantir igualdade de oportunidades para todos, em um contexto cujo principal produto é a desigualdade das condições de ensino e aprendizagem. Desigualdade que se reproduz discursivamente pelos sentidos de sucesso e fracasso, normalidade e anormalidade, localizadas nos próprios alunos. Diante dessas contradições, surge um desafio ao psicólogo escolar, cujo papel se confunde em meio aos anseios institucionais e às demandas da sociedade atual. 
Delineando a arena discursiva em que se constrói tal demanda para a intervenção da Psicologia na escola, a discussão dos resultados tem como um de seus objetivos sistematizar uma reflexão sobre os processos de normalização, naturalizados por práticas estigmatizantes e individualizantes, buscando sua ressignificação.

Pretende-se, neste momento, discutir as possibilidades de atuação da Psicologia, voltada à dimensão interdiscursiva das práticas escolares e das políticas inclusivas, a partir do referencial teórico de Mikhail Bakhtin.

\section{Discussão}

\subsection{A Psicologia na escola mediante a tarefa da inclusão: dificuldades, contradições e possibilidades}

A escola é um espaço onde são postas muitas expectativas por parte da sociedade, já que a educação escolar e as práticas de letramento nela dominantes constituem a forma de educação predominante.

A instituição escolar analisada neste estudo é mais um destes locais sobre os quais são depositadas muitas expectativas. Nela perpassam desejos, vontades, verdades, pensamentos e valores que se intercruzam constantemente através dos sentidos das relações sociais ali presentes. Os discursos (vozes) que explicitam esse tenso emaranhado de questões merecem ser ouvidos e refletidos.

A partir da análise documental das atividades realizadas pelos estudantes do curso de Psicologia, nos anos de 2004 e 2005, observou-se que o trabalho foi iniciado com grandes dificuldades. Os discursos escolares expressavam a necessidade da Psicologia quanto às práticas de escuta. Desenvolveram-se, portanto, oficinas de música como forma de praticar a escuta e contribuir para o diálogo na escola. Porém, apesar de a instituição demonstrar interesse pelo projeto de intervenção, ao mesmo tempo em que se queixava da não-escuta e se mostrava desejante de um espaço onde aprendessem a se ouvir, vários obstáculos interpelavam o início do projeto das oficinas, retratando o impasse, a contradição entre 0 querer escutar, fazer circular as vozes na escola, e recuar, monologizar, ensurdecer.

$\mathrm{Na}$ concepção bakhtiniana, estas dificuldades podem ser compreendidas a partir dos silêncios e impossibilidades de diálogo, uma vez que o enunciado não é somente o que está sendo dito pelo locutor, ele também possui um não-dito como parte constitutiva de seu processo de significação. O contexto extraverbal implica julgamentos de valor social que produzem efeitos sobre o dizer, englobando assim, questões que não são de âmbito pessoal, mas que dizem respeito ao outro, à historia e à memória social. 
Diante da multiplicidade de vozes presente na escola, de sua presença e de seus conflitos ou de seus silêncios, que falam sem dizer e agem sem permissão, como colocar em prática as políticas inclusivas? De que maneira a Psicologia pode contribuir com a tarefa da escola em lidar com a contradição do discurso?

Como conceber sujeitos excessivamente ativos, que dispõem sua energia à bagunça e à violência e, ao mesmo tempo, passivos, que não participam das aulas, sem, ao menos, ter vontade de questionar e adquirir novos conhecimentos? Por que o interesse é direcionado ao que não diz respeito ao aprendizado do conteúdo? Qual o sentido da prática de letramento escolar para seus membros? Esses questionamentos geram reflexões relacionadas à diversidade que habita a escola, aos vários interesses ali presentes e à grande dificuldade de lidar com essa vasta dispersão, que não segue um padrão e não se comporta de maneira regular e previsível. Como buscar a inclusão em meio a tantas diferenças? E indiferença!

No caso da escola analisada pelas pesquisadoras, por meio dos registros de um processo de intervenção psicológica, percebeu-se que o saber ouvir, em princípio, significava corrigir as bizarras expressões das crianças, que se davam em forma de rotas de fuga. Entretanto, esta tentativa de calar as formas de expressão dos alunos, de deter sua dispersão, pode ser vista como uma atitude monológica ineficaz, já que elas sempre encontrarão uma maneira de se enunciar. As vozes das crianças surgem de maneira bizarra, desviante, em algazarra, como um sintoma ou em silêncio, misturada, sem muito sentido (Pan, 2003).

Os alunos possibilitam, portanto, o dialogismo discursivo, mostrado às avessas. A indisciplina e a indiferença, apesar de serem atitudes aparentemente paradoxais, fazem parte do movimento de forças sociais contrárias. É o que Bakhtin (2008) caracteriza como o "riso", a "carnavalização", o discurso oficial às avessas, que tudo relativiza e descentraliza, mantendo a tensão sempre presente e, assim, desestabilizando um sistema que busca se manter monológico, afirmando-se como único e verdadeiro.

Quanto mais verdadeiro, e, portanto, autoritário é um discurso, mais monológico ele é. A sua heterogeneidade, multiplicidade e o dialogismo são ocultados por uma suposta voz única que detém o poder. Aqui, a exclusão se dá por meio de estratégias de regulação e de controle, tal como leis, costumes e moralidades, discursos e práticas institucionais estabelecidos através de relações de poder, 0 que assegura e garante identidades fixas, centradas, homogêneas e estáveis. (Duschatzky \& Skliar, 2001). Ao dizer "não somos ouvidos a maioria das vezes", a aluna da $8^{a}$ série indigna-se com a impossibilidade de falar diante uma única e verdadeira voz que está presente dentro da instituição, sem permitir a expressão das demais. 
A impossibilidade de falar e o estado de não ser ouvido é o que Bakhtin (1992) entende como o estado de não ser reconhecido, não ser lembrado. Ser é se comunicar, é ser para um outro; é dar lugar à alteridade. Negar a existência do outro seria uma atitude monológica, autocentrada e insensível às respostas do outro. O diálogo sem fim, insolúvel, sempre aberto, em constante construção e renovação é justamente uma maneira de sobrepujar o monologismo, preservando a liberdade do ser humano e de seu eterno inacabamento.

O dialogismo, desse modo, pode ser tomado como uma ética que possibilita entender os sentidos das tensões presentes nas relações como sua base constitutiva e não como desvio ou desequilíbrio. Nossa tarefa seria então, perscrutar: quais vozes se encontram caladas, emudecidas ou em ruídos, denunciando a ruína das relações de alteridade?

A instituição escolar estudada, ao mesmo tempo em que pede que os alunos ouçam os professores, não os ouve e nem às famílias, as quais são culpabilizadas. A presente análise promove a produção de outros sentidos para os problemas dos alunos, ressignificando-os enquanto problemas da escola como um todo, sem que haja um culpado para esta situação. Sob o efeito do discurso escolar, seus atores tentam se eximir dos problemas - dos alunos -, culpabilizando a família por seu abandono, reproduzindo assim a mesma lógica, diante da tarefa árdua e quase impossível de ensiná-los, colocando-os também reféns do abandono.

Nem mesmo os estudantes de Psicologia, chamados para realizar a escuta, são ouvidos pelos alunos. Consolidam-se assim, práticas que impossibilitam as relações de alteridade. Diante desta problemática, analisa-se o papel da Psicologia: como atuar diante desta complexa rede de relações e conflitos, agravada pelo imperativo moral da inclusão?

O psicólogo, enquanto especialista, é chamado em meio a este contexto, a fim de afirmar a lógica das cenas, atribuindo-lhes sentidos. A lista de situações críticas e afazeres é crescente, o que impõe ao psicólogo a necessidade de um trabalho ligeiro e eficiente, sob a pena de desqualificação profissional (Rocha, 2010). Assim, o projeto parece ter atingido seu objetivo de contrapor-se à demanda imediata de avaliação de estudantes problemáticos e de turmas indisciplinadas.

Ao analisarmos a prática desenvolvida, entendemos que ela procurou apontar meios de consolidar uma intervenção psicológica eticamente orientada, em um contexto de educação formal, visando escutar e fazer circular as vozes presentes na escola, de maneira a ressignificálas e Ihes atribuir outro tom valorativo. A queixa da não-escuta levou a equipe de Psicologia a trabalhar os sentidos das relações presentes na instituição, sensibilizando seus integrantes para a impossibilidade da escuta generalizada e, portanto, da inclusão das diferenças e do 
rompimento dos sentidos e sentimentos de indiferença. As turmas rotuladas permitiram que a escola se avaliasse em sua posição de negação da alteridade, não apenas àquelas turmas, mas a toda a escola.

Explicita-se, assim, a implicação da Psicologia em busca de um olhar institucional não apenas pelas técnicas aplicadas, mas pelos modos de produzir a interrupção na inércia do cotidiano daquela escola, ou no tédio institucional, conforme definido por Rocha (2000), e fazer pensar, dessacralizando as posições estereotipadas e hierarquizadas. Para avançar com a leitura bakhtiniana, segundo Jobim e Souza (2011), o método de intervenção e investigação utilizado reconhece e investe no dialogismo como forma de promover a tensão entre as vozes e seus silêncios, fazendo circular a palavra em suas múltiplas direções, de maneira a transparecer preconceitos e discriminações, bem como promover o exercício alteritário.

Entende-se, contudo, que dentre suas possibilidades encontram-se seus limites: uma sociedade orientada pelos princípios valorativos do pensamento neoliberal, em que as habilidades individuais são estimuladas no sentido da competição, pela responsabilização do indivíduo pelo seu sucesso ou fracasso, pelo enfraquecimento dos laços de solidariedade coletiva e dos sistemas de proteção social (Laplane, 2006), o individualismo e o não lugar à alteridade são algumas consequências, caracterizando um cenário contraditório ao proposto pela inclusão. Desse modo, ao invés de promoverem aquilo que afirmam querer promover - uma educação para todos -, as políticas de inclusão afirmam-se em sua contradição, contribuindo para uma inclusão excludente (Veiga-Neto, 2007).

Este é o desafio das práticas psicológicas que caminham para consolidar o direito de todos à educação; não só de estar na escola, mas de poder ser reconhecido, comunicar-se e ser ouvido, de se socializar para a vida e a saúde, e não para o sofrimento, para a impossibilidade de comunicação, a negação da alteridade.

\section{Considerações finais}

Este trabalho analisou uma prática psicológica realizada em uma escola pública e discutiu as contradições presentes nas relações intersubjetivas de seu cotidiano, produzidas a partir da implantação das políticas de inclusão. O trabalho, realizado por meio da análise dos discursos na perspectiva bakhtiniana, levantou uma série de questionamentos a nível institucional e social.

As políticas de educação inclusiva fundamentam-se em princípios morais e políticos estabelecidos em documentos nacionais e internacionais e na legislação que, aparentemente, visam garantir educação de qualidade a todos. "Entretanto, algumas questões 
permanecem: Por que é tão difícil implementar políticas de educação inclusiva? Por que é tão larga a brecha entre as políticas e as práticas?" (Laplane, 2006, p. 710).

Nossa análise é mais um estudo a confirmar essa distância. No entanto, buscamos assinalar o sofrimento presente no cotidiano da escola, primeiro, como forma de recortar o objeto de intervenção do psicólogo: a instituição inserida na totalidade social; segundo, não permitir que se considere a inclusão como uma prática fácil e individualizante, focalizada apenas na inserção de alunos com deficiências no ensino comum, explicitando assim suas tensões e conflitos; terceiro, enfrentar a crítica ao discurso da inclusão por meio da análise de uma intervenção que oportunize aos profissionais da Psicologia outras possibilidades de leitura dos discursos institucionais contraditórios, como direcionamento de práticas alternativas.

Nesse sentido, as práticas inclusivas convocam a todos, a fim de viabilizar o reconhecimento das diferentes formas de ensinar e aprender que se comprometam eticamente com a não individualização de problemas sociais, com a desconstrução discursiva do binômio normal-patológico, fazendo circular vozes e conflitos de forma a impedir a culpabilização excessiva dos alunos pelo insucesso escolar. À Psicologia cabe o papel de sistematizar e ampliar conhecimentos e práticas psicológicas que favoreçam a circulação da palavra, a garantia do diálogo e das relações saudáveis dentro da escola, sem que precisemos afirmar o imperativo moral da inclusão, como mais um dever a ser cumprido.

\section{Referências}

Amorim, M. (2012). Linguagem e memória como forma de poder e resistência. Bakhtiniana: Revista de Estudos do Discurso, 7(2), 19-37.

Bakhtin, M. (1990). Marxismo e Filosofia da Linguagem (M. Lahud e Y. F. Vieira, Trads.). (5a ed.). São Paulo: Hucitec. (Trabalho original publicado em 1929).

Bakhtin, M. M. (1992). Estética da criação verbal. São Paulo: Martins Fontes.

Bakhtin, M. M. (2008). A Cultura Popular na Idade Média e no Renascimento: o contexto de François Rabelais. (Yara Frateschi Vieira, Trad.). São Paulo: Hucitec; Brasília: Editora Universidade de Brasília.

Carone, I. (1998). Igualdade versus diferença: um tema do século. In J. G. Aquino (Org.). Diferenças e preconceito na escola: alternativas teóricas e práticas. (pp. 171-182). São Paulo: Summus. 
Castro, A. de Carvalho, Portugal, F. T., \& Jacó-Vilela, A. M. (2011). Proposição bakhtiniana para análise da produção em Psicologia. Psicologia em Estudo (Impresso), 16, 91-99.

Coutinho, L. G. (2011). Pesquisa-intervenção na escola: adolescência, educação e inclusão social. Arquivos Brasileiros de Psicologia, 63(1), 1-10.

Duschatzky, S., \& Skliar, C. (2001). O nome dos outros. Narrando a alteridade na cultura e na educação. In J. Larrosa, \& C. Skliar (Orgs.). Habitantes de Babel: políticas e poéticas da diferença. (pp. 119-138). Belo Horizonte: Autêntica.

Faraco, C. A. (2003). Criação ideológica e dialogismo. In C. A. Faraco (Org.). Linguagem e Diálogo: as idéias lingüísticas do círculo de Bakhtin. (pp. 45-85). Curitiba: Criar Edições.

Gentili, P. (1997). Adeus à escola pública: a desordem neoliberal, a violência do mercado e o destino da educação das maiorias. In P. Gentili (Org.). Pedagogia da exclusão: o neoliberalismo e a crise da escola pública. (pp. 228-252). (Coleção estudos culturais em educação). Petrópolis: Vozes.

Jobim e Souza, S., Camerini, M. F., \& Morais, M. C. (2000). Conversando com crianças sobre escola e conhecimento: abordagem dialógica e crítica do cotidiano. In S. Jobim e Souza (Org.). Subjetividade em questão: infahcia como crítica da cultura (pp. 139-153). Rio de Janeiro: 7 Letras.

Jobim e Souza, S. (2011). Por uma epistemologia da imagem técnica. Pesquisas e Práticas Psicossociais, 6(2), 206-210.

Jobim e Souza, S., \& Porto e Albuquerque, E. D. (2012). A pesquisa em ciências humanas: uma leitura bakhtiniana. Bakhtiniana: Revista de Estudos do Discurso, 7(2), 109-122.

Kassar, M. C. M. (2004). Matrículas de crianças com necessidades educacionais especiais na rede de ensino regular: do que e de quem se fala? In M. C. R. Góes, \& A. L. F. Laplane (Orgs.). Políticas e práticas de educação inclusiva. (pp. 49-68). (Coleção educação contemporânea). Campinas, SP: Autores Associados.

Laplane, A. L. F. (2004). Notas para uma análise dos discursos sobre inclusão escolar. In M. C. R. Góes, \& A. L. F. Laplane (Orgs.). Políticas e práticas de educação inclusiva (pp. 05-20). (Coleção educação contemporânea). Campinas, SP: Autores Associados.

Laplane, A. (2006). Uma análise das condições para implementação de políticas de educação inclusiva no Brasil e na Inglaterra. Educação e Sociedade, 27 (96 - Especial), 689-715.

Lei n. 10.172, de 09 de janeiro de 2001. (2001). Aprova o Plano Nacional de Educação e dá outras providências. Brasília, DF: Presidência da República. Recuperado em 01 setembro, 2014, de

http://www.planalto.gov.br/ccivil_03/leis/leis_2001/l10172.htm 
Lei n. 13.005, de 25 de junho de 2014. (2014). Aprova o Plano Nacional de Educação - PNE e dá outras providências. Brasília, DF: Presidência da República. Recuperado em 03 setembro, 2014, de http://www.planalto.gov.br/ccivil_03/_Ato20112014/2014/Lei/L13005.htm

Machado, J. P., \& Pan, M. A. G. de S. (2012). Do nada ao tudo: políticas públicas e a educação especial brasileira. Educação e Realidade, 37(1), 273-294.

MEC (1994). Declaração de Salamanca e linha de ação sobre necessidades educativas especiais. (1994). Brasília, DF: CORDE.

Pan, M. A. G. de S. (2003). Infância, discurso e subjetividade: uma discussão interdisciplinar para uma nova compreensão dos problemas escolares. Tese de Doutorado, Linguística, Universidade Federal do Paraná, Curitiba, PR, Brasil.

Pan, M. A. G. de S. (2007, abril). Letramento e a produção da anormalidade: uma reflexão sobre as práticas pedagógicas e a inclusão escolar. In Anais do VIII Congresso Nacional de Psicologia Escolar e Educacional, VIII Congresso Nacional de Psicologia Escolar e Educacional. São João Del-Rei: Associação Brasileira de Psicologia Escolar e Educacional.

Poças, A. C., Quandt, A. C., Jamus, D. R., \& Menegusto, K. (2005). Relatório Final de Estágio. Trabalho de conclusão de estágio não publicado. Curso de Psicologia, Universidade Federal do Paraná, Curitiba,PR, Brasil.

Rocha, M. L. (1999). A formação na interface Psicologia/Educação: novos desafios. In A. M. Jacó-Vilela, \& Mancebo, D. (Orgs.). Psicologia Social: abordagens sócio-históricas e desafios contemporâneos. (pp. 183-194). Rio de Janeiro: EdUERJ.

Rocha, M. L. (2000). Educação em tempos de tédio: um desafio à micropolítica. In E. Tanamashi, M. L., Rocha, \& M. Proença (Orgs.). Psicologia e educação: desafios teórico-práticos (pp. 185-207). São Paulo: Casa do Psicólogo.

Rocha, M. L., \& Aguiar, K. F. de. (2010). Entreatos: percursos e construções da psicologia na rede pública de ensino. Estudos e Pesquisas em Psicologia, 10 (1), 68-84.

UNESCO (1998). Declaração Mundial sobre Educação para Todos: satisfação das necessidades básicas de aprendizagem. Jomtien, 1990. Recuperado em 01 setembro, 2014, de http://unesdoc.unesco.org/images/0008/000862/086291por.pd $f$

Veiga-Neto, A., \& Lopes, M. C. (2007). Inclusão e governamentalidade. Educação e Sociedade, 28 (100 Especial), 947-963.

\section{Endereço para correspondência}




\section{Miriam Aparecida Graciano de Souza Pan}

Universidade Federal do Paraná

Setor de Ciências Humanas Letras e Artes - Departamento de Psicologia

Praça Santos Andrade, $2^{\circ}$ andar sala 216 - Centro, CEP 80060-000, Curitiba - PR, Brasil

Endereço eletrônico: miriamagspan@yahoo.com.br

\section{Maiana Jugend Zugman}

Tribunal de Justiça do Paraná - Fórum da Família, da Infância e do Adolescente

Núcleo Integrado de Apoio Psicossocial

Rua da Glória, 290, 70 andar - Centro Cívico, CEP 80030-060, Curitiba - PR, Brasil

Endereço eletrônico: maianaj@hotmail.com

Recebido em: 12/09/2014

Reformulado em: 11/11/2014

Aceito para publicação em: 11/11/2014

\section{Notas}

* Doutora em Letras pela Universidade Federal do Paraná, realizou pesquisa de pós-doutoramento sobre políticas inclusivas na Universidade do Texas, em Austin, com bolsa CAPES. Professora do Departamento de Psicologia da Universidade Federal do Paraná no Programa de Pós-graduação em Psicologia, onde é Líder do Grupo de Pesquisa intitulado Psicologia, Educação e Trabalho.

** Psicóloga do Tribunal de Justiça do Paraná - TJPR. Atua nas Varas de Família de Curitiba. Participou da pesquisa "Práticas de Letramento e Processos Subjetivos: um estudo sobre exclusão escolar", como aluna de Iniciação Científica em 2007 e 2008, bem como do Projeto de Extensão "Letramento e Inclusão Social", ambos da Universidade Federal do Paraná - UFPR, Curitiba, Paraná, Brasil. 